\title{
Traceless Photolabile Linker Expedites the Chemical Synthesis of Complex Oligosaccharides by Automated Glycan Assembly
}

\author{
Kim Le Mai Hoang, ${ }^{\dagger}$ Alonso Pardo-Vargas, ${ }^{\dagger, \dagger}$ Yuntao Zhu, ${ }^{\dagger}$ Yang Yu, ${ }^{\dagger,}$ Mirco Loria, ${ }^{\dagger}$ \\ Martina Delbianco, ${ }^{+}$a a \\ ${ }^{\dagger}$ Department of Biomolecular Systems, Max-Planck-Institute of Colloids and Interfaces, Am Mühlenberg 1, 14476 Potsdam, \\ Germany \\ ${ }^{\ddagger}$ Institute of Chemistry and Biochemistry, Freie Universität Berlin, Arnimallee 22, 14195 Berlin, Germany
}

Supporting Information

ABSTRACT: Automated glycan assembly (AGA) aims at accelerating access to synthetic oligosaccharides to meet the demand for defined glycans as tools for molecular glycobiology. The linkers used to connect the growing glycan chain to the solid support play a pivotal role in the synthesis strategy as they determine all chemical conditions used during the synthesis and the form of the glycan obtained at the end of it. Here, we describe a traceless photolabile linker used to prepare carbohydrates with a free reducing end. Modification of the $o$-nitrobenzyl scaffold of the linker is key to high yields and compatibility with the AGA workflow. The assembly of an
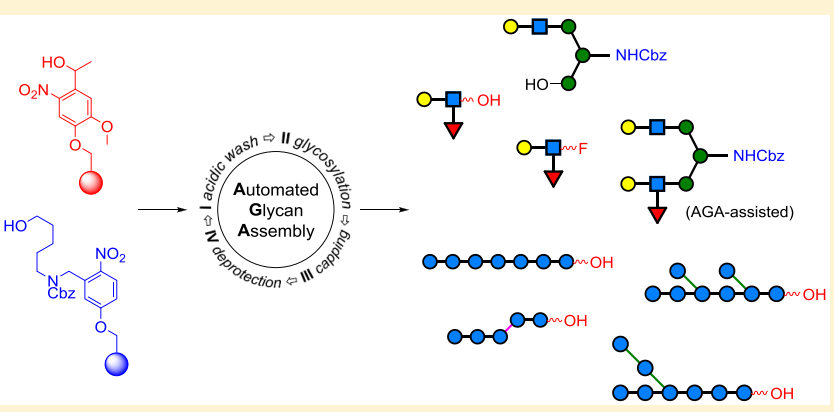
asymmetrical biantennary $N$-glycan from oligosaccharide fragments prepared by AGA and linear as well as branched $\beta$ oligoglucans is described to illustrate the power of the method. These substrates will serve as standards and biomarkers to examine the unique specificity of glycosyl hydrolases.

\section{INTRODUCTION}

The procurement of complex oligosaccharides in satisfactory quantities and quality as tools for glycobiology remains challenging. Harvesting from natural sources is untenable because the post-translational glycosylation pathway is heavily influenced by minute changes in the environment of the living cell, leading to multiple glycoforms. ${ }^{1}$ At present, chemical and enzymatic approaches, or combinations thereof, are often the only reliable methods to access pure glycans. ${ }^{2}$ Efforts to reduce the time and resources spent on traditional chemical syntheses have focused mainly on automated glycan assembly (AGA) ${ }^{3}$ and computer-assisted one-pot synthesis. ${ }^{4}$

AGA relies on the delivery of building blocks to a suspension of a solid support that is equipped with a linker, followed by the addition of a suitable activating solution using either homebuilt instruments or the commercial Glyconeer 2.1 glycan synthesizer. ${ }^{5}$ Precise control of important reaction parameters such as temperature and concentration under an inert atmosphere allows for nearly quantitative coupling of building blocks to the resin. Repetitive cycles consisting of glycosylation, capping, and selective deprotection steps extend the glycan chain to the desired structure. Different linkers for AGA were explored (Figure 1), including metathesis-labile linker $1{ }^{6}$ base-labile linker $2,^{7}$ and photocleavable linkers 3 and 4 . $^{8}$ Photocleavable linkers such as $\mathbf{3}$ and $\mathbf{4}$ are often referred to as "traceless" because the on-resin removal of photosensitive groups requires exposure only to light to release the product into the solution. They have proven to be stable under both acidic and basic conditions and are compatible with a wide range of protecting groups such as carbonates (9-fluorenylmethoxycarbonyl, Fmoc), esters (levulinoyl, Lev and benzoate, $\mathrm{Bz}$ ), and ethers (benzyl, Bn). These linkers are cleaved to afford glycans carrying an aminoalkyl spacer at the reducing end. The resulting oligosaccharides, after global deprotection, are ready for conjugation to carrier proteins to give glycoconjugate vaccine candidates ${ }^{9}$ or to be immobilized on microarrays for the high-throughput analysis of proteincarbohydrate interactions. ${ }^{10}$

Here, we report the design and use of spacer-free photolabile linker 5 that retains excellent chemical orthogonality and enables access to protected glycans with a free reducing end. These in turn can be transformed into the corresponding glycosyl fluorides, phosphates, and trichloroacetimidates. Oligosaccharide fragments produced in this way can be united in block couplings to prepare more complex polysaccharides. Furthermore, free reducing glycans are valuable analytical standards for inspecting fragmentation patterns in tandem mass spectrometry ${ }^{11}$ or for glycosynthase assays that demand linker-free glycan epitopes as precursors. Photolabile linker $\mathbf{5}$ offers flexibility compared to previous methods, ${ }^{12}$ which prepared glycans with a benzyl group at the reducing terminus. New linker $\mathbf{5}$ is illustrated for the AGA of a penta- and a trisaccharide that are combined in a $[5+3]$ glycosylation

Received: April 8, 2019

Published: May 15, 2019 




metathesis labile
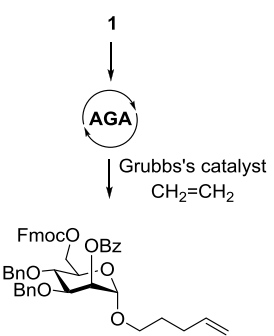

1. $\mathrm{NaOMe}, \mathrm{MeOH}$

$$
\text { 2. } \mathrm{H}_{2}, \mathrm{Pd} / \mathrm{C}
$$

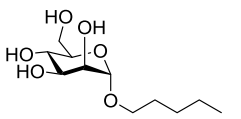

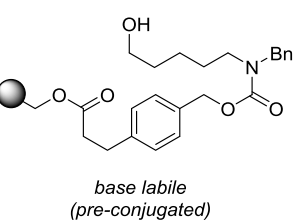

(pre-conjugated)

2

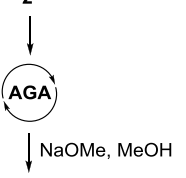

${ }^{\mathrm{HO}} \mathrm{OH}$



$\mathrm{H}_{2}, \mathrm{Pd} / \mathrm{C}$

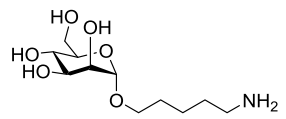

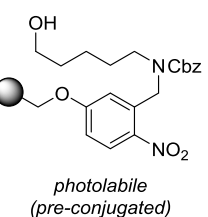

(pre-conjugated)

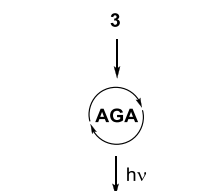

(O)

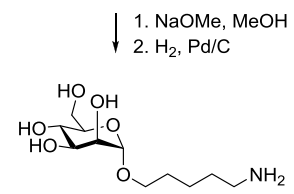

$\mathrm{OH}$
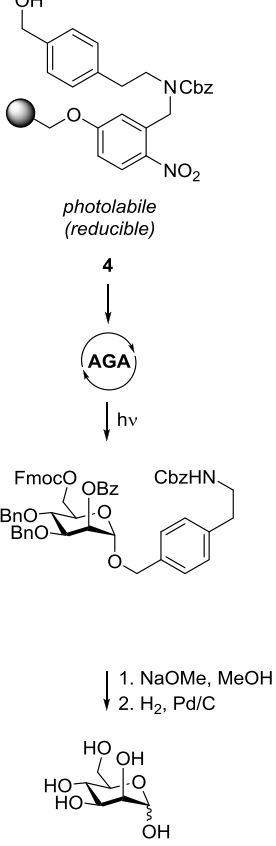

${ }^{*}$ this work

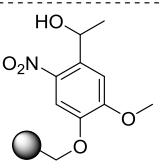

photolabile

(reducible)

5
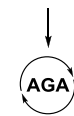

$\downarrow h v$

$\mathrm{FmocO}_{\mathrm{OBz}}$

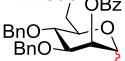

OH

$\downarrow$

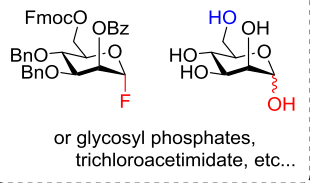

Figure 1. Linkers for AGA.

strategy to obtain an asymmetric biantennary $N$-glycan fragment. Additionally, several structurally defined linear and branched laminarin $\beta$-(1,3)-oligoglucans are prepared, which will be instrumental in elucidating the hydrolytic mechanism of various hydrolases from marine bacteria. Investigations into these highly specific processes are hampered by the lack of high-purity $\beta$-glucans from seawater that contain heterogeneous glycans released by different microbial species.

\section{RESULTS AND DISCUSSION}

Design and Synthesis of Photolabile Linkers. One of the most frequently used photolabile groups ${ }^{13}$ to date is methyl-6-nitroveratryl (MeNV), which introduces two modifications to the $o$-nitrobenzyl (oNB) scaffold: the $\alpha$-methyl group at the benzylic carbon and two methoxy groups on the aromatic ring. The methyl group was thought to improve the chemical yield by the release of a ketone byproduct instead of an aldehyde, which is less prone to side reactions. ${ }^{13}$ Meanwhile, the introduction of electron-donating substituents on the aromatic ring increases the absorption coefficient at longer wavelengths to match the peak emission at $366 \mathrm{~nm}$ from a mercury UV lamp. ${ }^{14}$ A design based on the MeNV motif should improve the photocleavage process. To provide an anchor point to the solid support, one of the methoxy groups in MeNV was substituted. Three different MeNV-type linkers (5, 6, and 7; Figure 2) were prepared starting from apocynin, an abundant plant extract. After photocleavage, the resin equipped with linker $\mathbf{5}$ will produce spacer-free reducible glycans while linker 6 returns glycans with the aminoalkyl spacer and linker 7 produces benzyl-protected glycans at the reducing end. For a direct comparison, oNB-type linkers 8 and 3 were prepared to provide the same products as linkers 5 and 6. Resin loading was determined for each batch of resin by the glycosylation of $50 \mathrm{mg}$ of resin with 6-O-Fmoc mannose building block $\mathbf{A}$ on the synthesizer (Scheme 2). Cleavage of the Fmoc group present on the solid support was quantified by
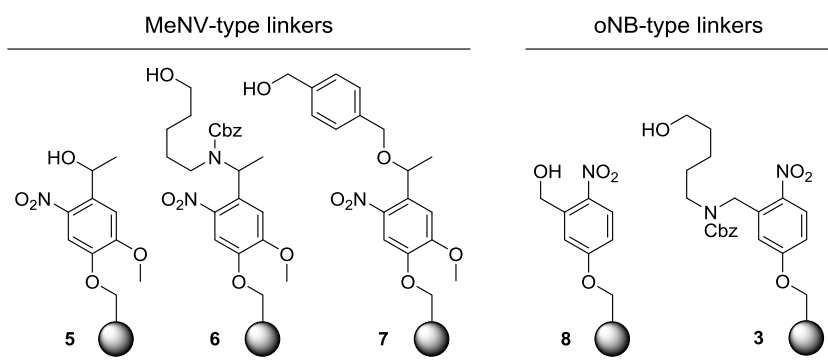

Figure 2. Merrifield resins functionalized with photolabile linkers for AGA.

UV-vis spectrophotometry ${ }^{15}$ and revealed loading values ranging from 0.32 to $0.36 \mathrm{mmol} / \mathrm{g}$.

Linker 8 was prepared by the reduction of 5-hydroxy-2nitrobenzaldehyde 9 and immobilization on Merrifield resin by heating with $\mathrm{Cs}_{2} \mathrm{CO}_{3}$ in the presence of catalytic amounts of TBAI (Scheme 1A). Linker 3 was prepared starting from the reductive condensation of 9 with 5-amino-pentan-1-ol to yield 11 in $85 \%$ yield. ${ }^{8}$ The addition of $\mathrm{Cbz}$ to the secondary amine was followed by immobilization onto the Merrifield resin to obtain linker-equipped resin 3 (Scheme 1B).

Syntheses of linkers containing the MeNV scaffold started from allyl-protected apocynin 12, which was selectively nitrated with $\mathrm{KNO}_{3}$ in TFA. This reaction is very sensitive to the initial temperature ${ }^{16}$ because dinitrated products were formed when a slight excess of $\mathrm{KNO}_{3}$ was introduced at $25^{\circ} \mathrm{C}$. Reactions initiated at $0{ }^{\circ} \mathrm{C}$ produced only trace amounts of 13 . The reaction proceeded best when $\mathrm{KNO}_{3}$ was added portionwise at exactly $10{ }^{\circ} \mathrm{C}$, followed by heating at $60{ }^{\circ} \mathrm{C}$ for $4 \mathrm{~h}$ to give mononitro 13 selectively (59\% conversion starting from 12). Next, the reduction of the ketone and cleavage of the allyl group employing $\mathrm{Pd}\left(\mathrm{PPh}_{3}\right)_{4}$ proceeded smoothly to provide precursor 15, which was ready for conjugation with the resin to give linker 5 (Scheme 1C). Utilizing intermediates 13 and 14, the $N$-linked and $O$ - 
Scheme 1. Synthesis of Photolabile Linkers

A

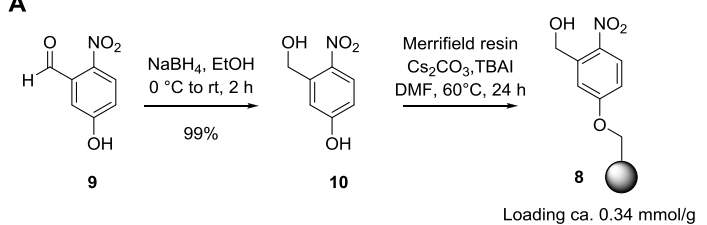

B

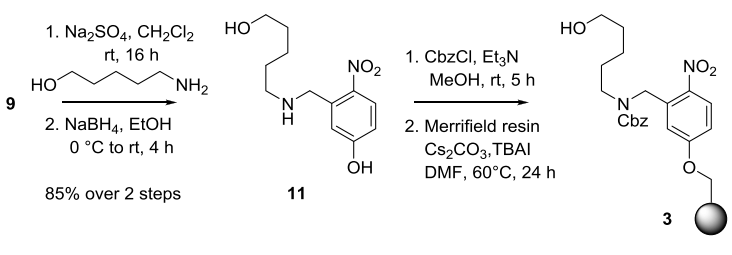

C

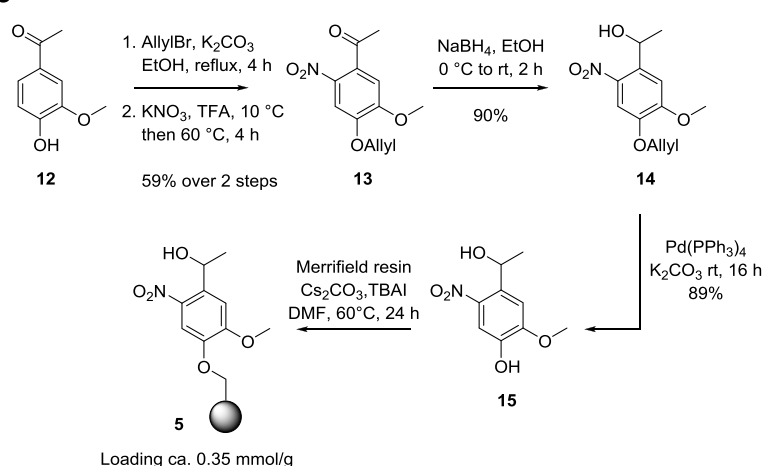

D
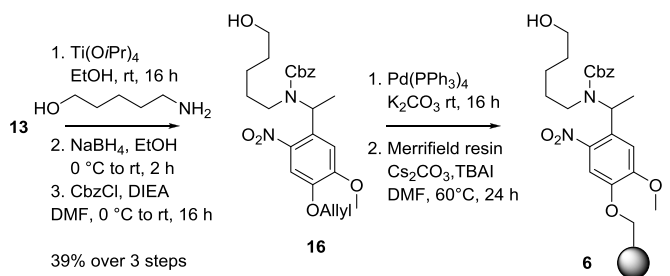

Loading ca. $0.32 \mathrm{mmol} / \mathrm{g}$

E



benzylether-linked variations of linker 5 were prepared. The reductive amination of ketone $\mathbf{1 3}$ was known for its poor yield. ${ }^{17}$ Reasonable conversion was achieved by using Ti$(\mathrm{OiPr})_{4}$ in a one-pot transformation of $\mathbf{1 3}$ to Cbz-protected compound 16 (39\% over three steps). ${ }^{18}$ Removal of the allyl group and on-resin functionalization afforded linker $\mathbf{6}$ (Scheme 1D). Double deallylation of $\mathbf{1 7}$ to linker 7 proceeded best when 1,3-dimethylbarbituric acid replaced $\mathrm{K}_{2} \mathrm{CO}_{3}$ as a scavenger in which the latter failed to completely remove the protecting groups (Scheme 1E).

Evaluation of Photolabile Linkers for AGA. With the photocleavable linkers in hand, the evaluation of the supportbound photolytic process was based on the quantity of fully protected oligosaccharides released after cleavage (Scheme 2).
Recovery of the cleaved product is an important parameter that emphasizes the practical utility of each functionalized resin. The automated synthesis of tetra-mannose $\mathbf{2 2}$ proceeded as follows: functionalized resin $3(40 \mathrm{mg}=0.013 \mathrm{mmol})$ was placed in the reaction vessel before acidic wash module I was executed (TMSOTf in $\mathrm{CH}_{2} \mathrm{Cl}_{2}$ at $-20{ }^{\circ} \mathrm{C}$ for $3 \mathrm{~min}$ ) to remove any residual base and water from the resin. Next, module IIa delivered 6.5 equiv of mannose $\mathbf{A}$ and a solution of activator (NIS/TfOH in $\mathrm{CH}_{2} \mathrm{Cl}_{2}$ /dioxane, $-20{ }^{\circ} \mathrm{C}$ for $5 \mathrm{~min}$ and then $0{ }^{\circ} \mathrm{C}$ for $20 \mathrm{~min}$ ) to the reaction vessel. Capping module III ( $\mathrm{MsOH}$ in $\mathrm{Ac}_{2} \mathrm{O} / \mathrm{CH}_{2} \mathrm{Cl}_{2}, 20 \mathrm{~min}$ ) masked any unreacted hydroxyl groups, followed by cleavage of the Fmoc carbonate on the C-6 hydroxyl group with module IVa (20\% piperidine in DMF, $5 \mathrm{~min}$ ). Module sequence I-IIa-III-IVa was repeated four times to obtain resin-bound tetra-mannose 22. Cleavage of $\mathbf{2 2}$ from the solid support was achieved using a continuous flow photoreactor. ${ }^{19}$ Monomannose, tetra- $\alpha-(1,6)$ mannose, and hexa- $\beta$ - $(1,4)$-glucose were assembled on resins equipped with different linkers. All linkers proved to be compatible with all standardized AGA protocols. No trace of deletion sequences was observed in any of the HPLC chromatograms of the crude products after photocleavage. Thus, differences in the isolated yield should correlate exclusively with the photolytic sensitivity of each linker. Linkers $\mathbf{5}$ and $\mathbf{8}$, for example, both delivered the free reducing end sugars but differed significantly in their photolytic efficiency. For $o$ NB-type linker 8 , the highest conversion observed was monomer 18 at only $34 \%$, with even lower yields for tetra-mannose $(21,22 \%)$ and hexa-glucose $(\mathbf{2 4}, 17 \%)$. In contrast, MeNV-type linker 5 consistently delivered the same products in $65-70 \%$ yield. $O$-linked resin 5 performed best in this study, surpassing both the $\mathrm{N}$-linked resin 6 and $\mathrm{O}$-Bnlinked resin 7.

The resin equipped with $N$-linked $o$ NB 3 outperformed $N$ linked MeNV-type resin 6 in all experiments to procure 5aminopentyl mannoside 19, tetra-mannoside 22, and hexaglucoside 25. Still, the resin with linker 6 released more product than with linker 8 . The photolytic sensitivity of $\mathrm{O}-\mathrm{Bn}$ linked resin 7 was found to be between that of the $N$-linked resins 3 and 6 . The following order of photocleavage performance was observed: $5>3>7>6>8$ (direct $O$ linked MeNV-type $>N$-linked oNB-type $>\mathrm{O}$-Bn-linked MeNV-type $>N$-linked MeNV-type $>$ direct $O$-linked $o$ NBtype). This seemingly counterintuitive series highlights one of the caveats when picking a suitable photocleavable scaffold for a specific leaving group. The photolytic process depends on the nature of both the leaving groups and the photolabile core. ${ }^{20}$ Hence, to prepare reducible glycans by AGA, the use of MeNV-type linker 5 or 7 is most efficient. For conjugationready oligosaccharides carrying a terminal amine, the best option is oNB-type linker 3.

Assembly of an Asymmetric $\mathrm{N}$-Glycan Fragment. AGA of asymmetrically branched octasaccharide 27, present in complex-type $\mathrm{N}$-glycans, ${ }^{21-24}$ served to illustrate the utility of the new linker (Figure 3 ). The complexity of $N$-glycans and their biological importance have rendered them attractive targets for testing chemical ${ }^{25-28}$ and chemoenzymatic synthesis methods. ${ }^{29-32}$ Following the convergence strategy employed by most solution-phase syntheses of biantennary $N$-glycans, we embarked on a $[5+3]$ glycosylation strategy. Target oligosaccharide 27 was constructed by the union of trisaccharide donor $\mathbf{2 8}$ and pentasaccharide acceptor 29, which were both prepared by AGA (Figure 3). Resins with 


\section{Scheme 2. Comparison of Photolabile Linkers}

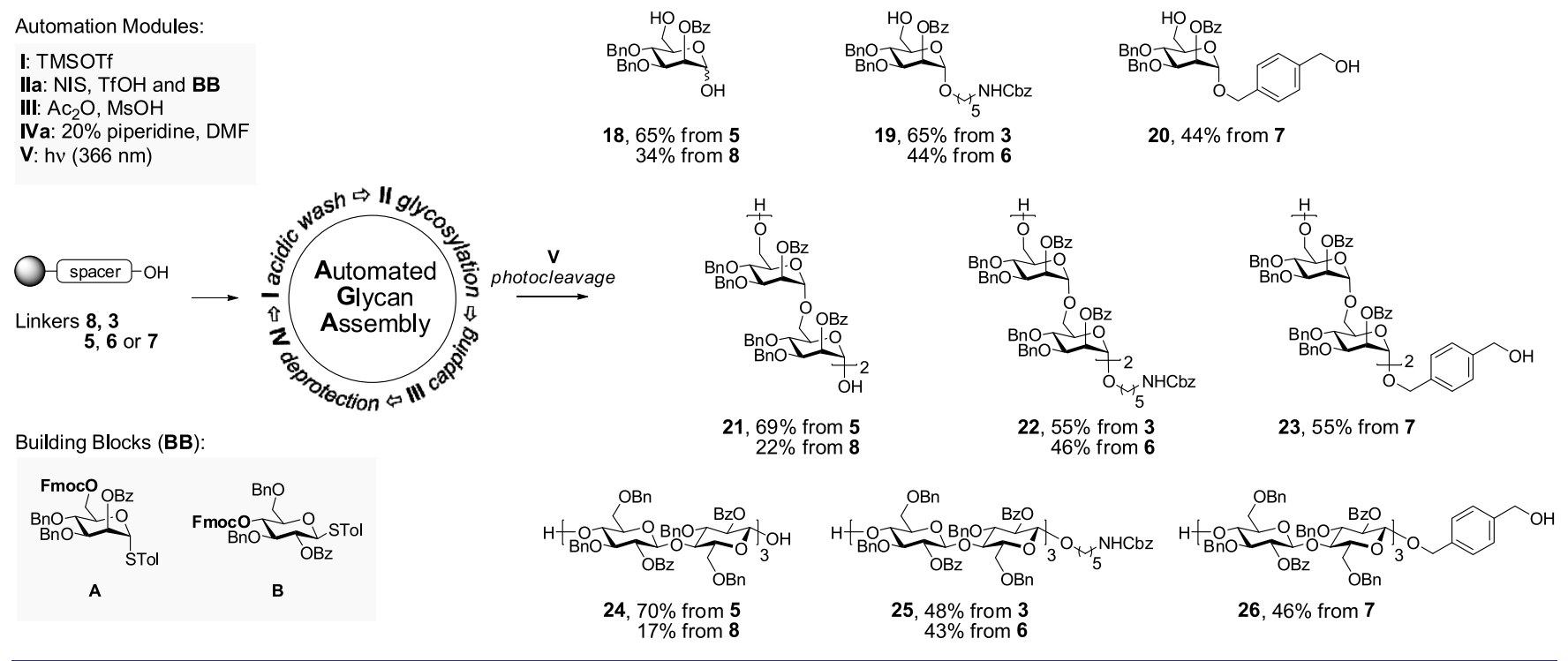

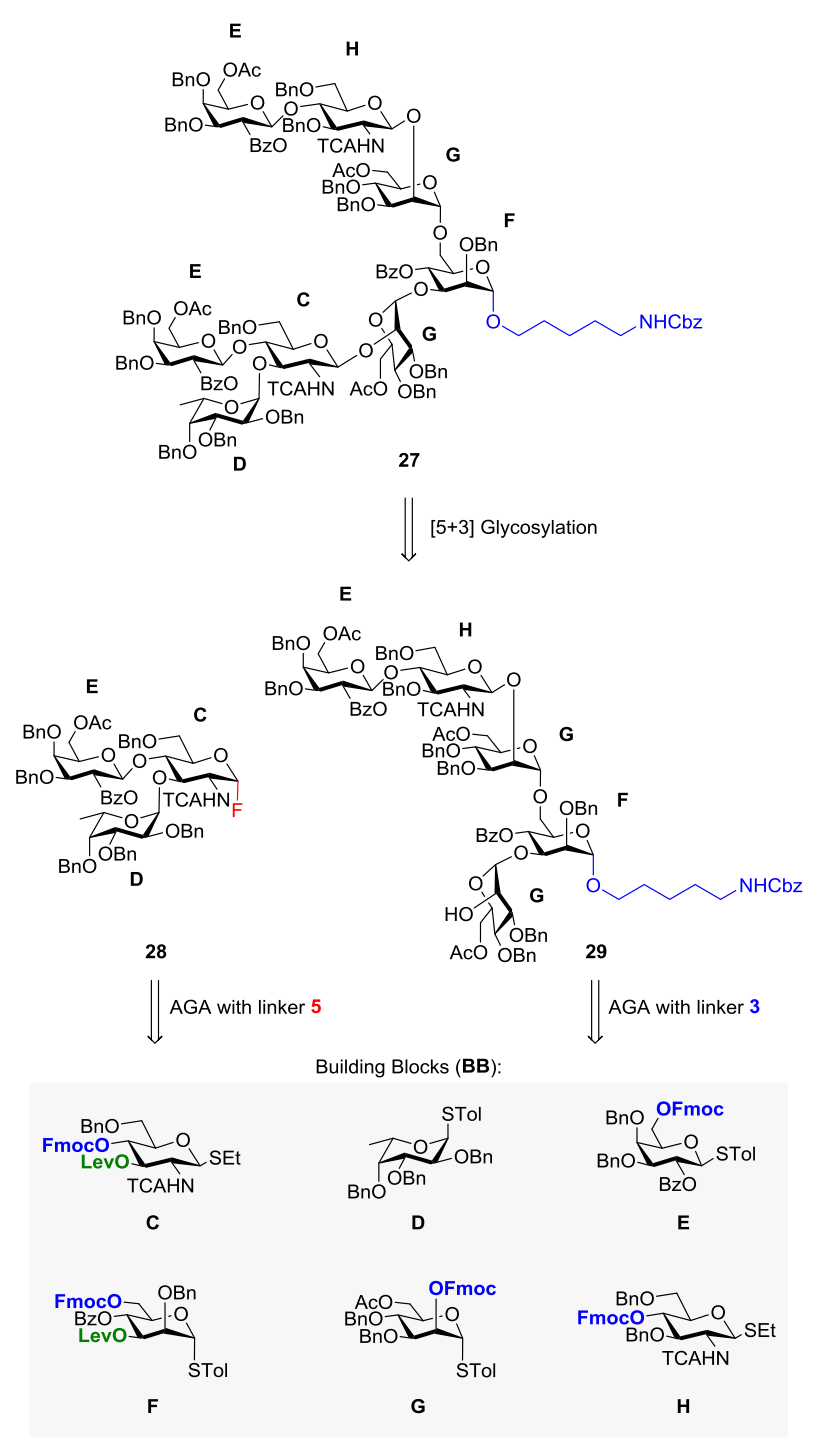

Figure 3. Retrosynthetic analysis of octasaccharide 27. photocleavable linkers 5 and 3 and six commercially available building blocks $(\mathbf{C}-\mathbf{H})$ were employed in the automated syntheses.

The automated synthesis of donor $\mathbf{2 8}$ commenced with glucosamine C (Figure 4), and the orthogonal removal of

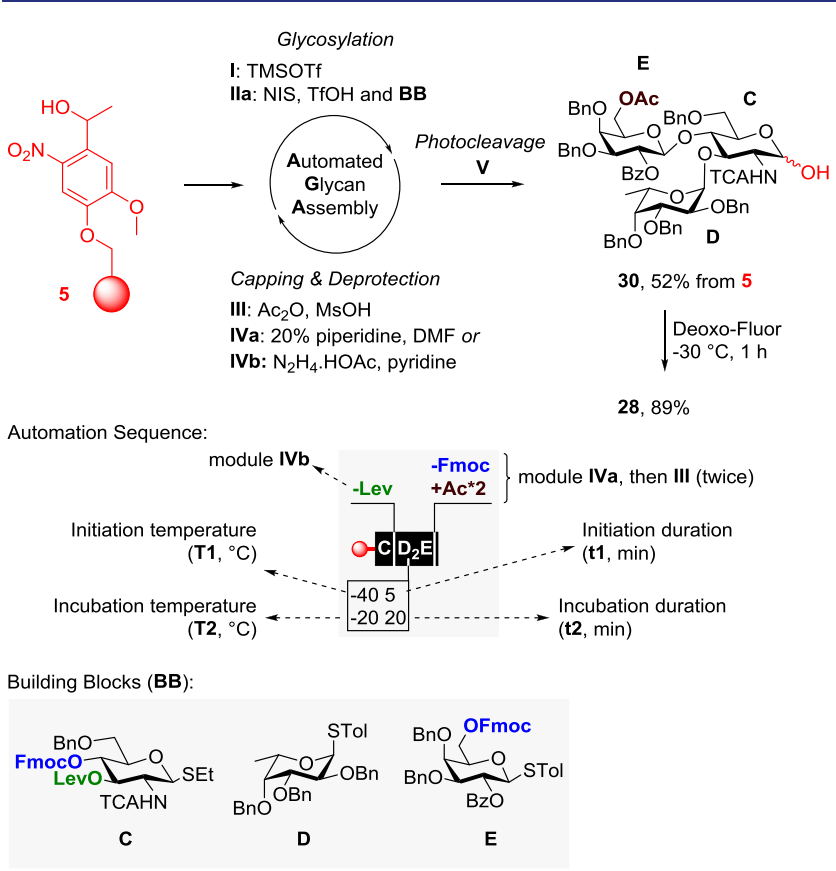

Figure 4. Automated synthesis of trisaccharide donor 28. A typical glycosylation cycle included module sequence I-IIa-III-IVa, represented by the letter of the building block being used (e.g., C). Changes in the sequence or parameters are indicated with a broken line and a box.

levulinoyl ester at the $\mathrm{C}-3$ position was achieved by executing module IVb $\left(\mathrm{N}_{2} \mathrm{H}_{4} \cdot \mathrm{HOAc}\right.$ in pyridine $)$. Stereoselective $\alpha$ fucosylation was secured by running glycosylation module IIa twice for fucose $\mathrm{D}$ at lower temperature $\left(-40{ }^{\circ} \mathrm{C}\right.$ for $5 \mathrm{~min}$ and then at $-20{ }^{\circ} \mathrm{C}$ for $20 \mathrm{~min}$ ). The Fmoc group at the $\mathrm{C}-4$ position of $\mathbf{C}$ was removed with module IVa (20\% piperidine in DMF). Next, modules I-IIa-IVa-III were executed to 
introduce galactose $\mathbf{F}$ as the third sugar. By capping after the deprotection module, the Fmoc group at C-6 of galactose $\mathbf{E}$ was converted to the more resilient acetate group. At any point during the automated process, a small amount of resin could be extracted and irradiated using a portable UV lamp (6 W, $366 \mathrm{~nm}$ ) for $10 \mathrm{~min}$ to release the glycans from the solid support. This convenient real-time monitoring of the reaction progress via HPLC and MALDI analysis helped to optimize the reaction conditions and identify potential problems. Photocleavage from the solid support afforded trisaccharide 30 as a mixture of $\alpha / \beta$-anomers in $52 \%$ yield. Fluorination of 30 by Deoxo-Fluor yielded glycosyl fluoride $\mathbf{2 8}$ in $89 \%$ yield after HPLC purification. Glycosyl fluorides are glycosyl donors for both chemical ${ }^{33}$ and enzymatic ${ }^{34}$ trans-glycosylation reactions.

With glycosyl donor $\mathbf{2 8}$ in hand, the automated synthesis of glycosyl acceptor 29 was initiated (Figure 5). Branching at the C-6 position of mannose $\mathbf{F}$ was achieved via the stepwise introduction of mannose $\mathbf{G}$, glucosamine $\mathbf{H}$, and galactose $\mathbf{E}$ with the on-resin capping of C-6 as the acetyl ester (module IVa and then III). The Lev ester on mannose $\mathbf{F}$ was cleaved to reveal the C-3 hydroxyl group, ready for branching with mannose building block $\mathbf{G}$. Fmoc removal on $\mathbf{G}$ concluded the



Building Blocks (BB):

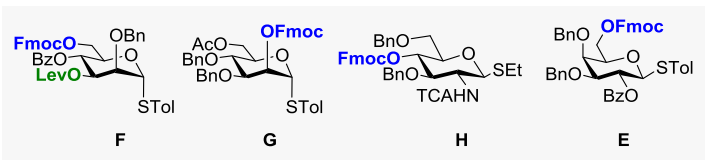

B
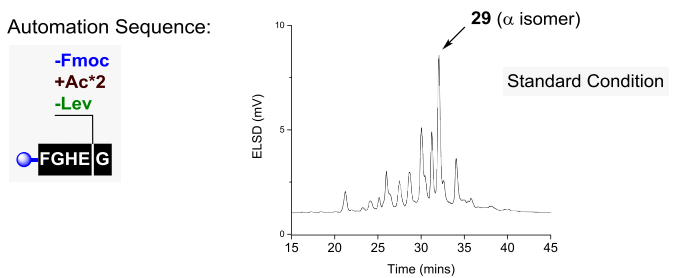

C
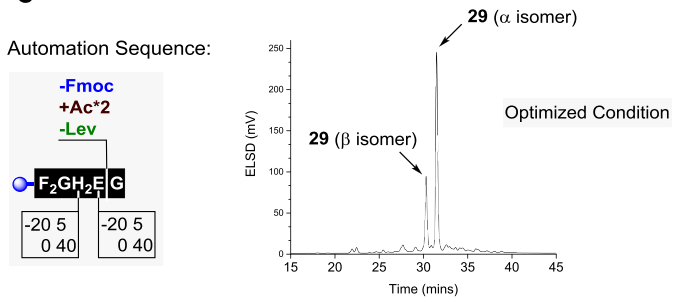

Figure 5. (A) Automated synthesis of pentasaccharide acceptor 29 using building blocks E-H. (B) Standard AGA condition leading to complicated HPLC traces of crude products. (C) Optimized condition revealing glycan 29 as a mixture of diastereoisomers. automated sequence before photolytic release furnished acceptor 29 (Figure 5A). However, building block sequence FGHEG was not crowned by success. An analysis of the crude mixture by HPLC and MALDI revealed the presence of several deletion sequences and regioisomeric products (Figure 5B). Deletion sequences resulting from incomplete couplings were avoided by using the glycosylation modules twice on unreactive building blocks such as $\mathbf{F}$ and $\mathbf{H}$. Fmoc cleavage using piperidine was previously found to be accompanied by the partial migration of Lev to the liberated hydroxyl group. ${ }^{35}$ This unwanted byproduct was not formed when $\mathrm{Et}_{3} \mathrm{~N}$ was used as a base. Thus, we introduced deprotection module IVc $(20 \%$ $\mathrm{Et}_{3} \mathrm{~N}$ in DMF) to replace module IVa. Glycosylation module IIa was used twice for building blocks $\mathbf{F}$ and $\mathbf{H}$. The coupling time needed to introduce building blocks $\mathbf{H}$ and $\mathbf{E}$ was increased from 20 to $40 \mathrm{~min}$. Gratifyingly, refined building block sequence $\mathbf{F}_{2} \mathbf{G H}_{2} \mathbf{E G}$ significantly improved the synthesis, as evident from the HPLC traces of the crude product showing only two peaks (Figure 5C). The structural analysis of each compound revealed that the main glycan was acceptor 29 and the minor was its diastereoisomer having an aberrant Man- $\beta$ $(1,3)$-Man glycosidic bond with a ${ }^{1} J_{\mathrm{C}, \mathrm{H}}$ value of $160 \mathrm{~Hz}$ at 95.8 ppm (Figure 5A, circled in red). To support this assignment, AGA of glycan sequence $\mathbf{F}_{2} \mathbf{G H}_{2} \mathbf{E}$ proceeded smoothly to afford the congener tetrasaccharide as the sole product (SI, compound S6). The poor stereoselectivity $(\alpha / \beta=3: 2)$ of the last glycosylation cycle leading to 29 was unexpected because the preliminary screening ${ }^{36}$ of all building blocks showed excellent selectivity. The "double stereodifferentiation" effect, also referred to as the "matched and mismatched" principle, may account for the stereochemical scrambling in the synthesis of $\beta$-(1,3)-glucans. ${ }^{37} \mathrm{~A}$ similar mechanism could be responsible for the substantial ratio of $\beta$-isomer of 29 .

With both glycosyl donor 28 and glycosyl acceptor 29 in hand, the glycosylation reaction promoted by AgOTf/ $\mathrm{Cp}_{2} \mathrm{HfCl}_{2}$ furnished octasaccharide 27 in $21 \%$ isolated yield (Scheme 3). An aliquot taken from the reaction vial after $4 \mathrm{~h}$ was analyzed by analytical HPLC and showed the nearly complete disappearance of donor 20. Product 27 was found to elute in close proximity to glycosyl acceptor 29. The fraction containing only glycan 27 was collected, and ${ }^{1} \mathrm{H}$-, ${ }^{13} \mathrm{C}$-, and coupled HSQC-NMR experiments confirmed the homogeneity of the sample, indicating a successful $\beta$-glucosamidation. The synthesis of asymmetrical $\mathrm{N}$-glycan octasaccharide 27 from glycan fragments prepared by AGA highlights the utility of traceless photolabile linker $\mathbf{5}$ for the convergent synthesis of complex oligosaccharides.

Automated Synthesis of Oligo- $\beta$-glucans. Marine algae are major carbon sinks that convert carbon dioxide to carbohydrate materials such as laminarin, an oligosaccharide comprising $\beta$-(1,3)-linked glucose with variable degrees of $\beta$ $(1,4)$ - and $\beta$-(1,6)-glucose residues in the backbone and the branches. Studies concerning the laminarin hydrolase mechanism require homogeneous $\beta$-(1,3)-glucans. Traceless resin 5 expedites the automated synthesis of oligosaccharides that serve as analytical standards and substrates for investigating the ecological roles of laminarin.

Convergent solution-phase syntheses of $\beta$-(1,3)-glucans were hampered by low yields and aberrant $\alpha$-linkage formation due to double-stereodifferentiation effects as well as limitations in the chain length, position, and degree of branching. AGA of linear and branched $\beta$-(1,3)-glucans carrying an aminoalkyl spacer at the reducing end was achieved earlier using glycosyl 
Scheme 3. Assembly of Octasaccharide 27

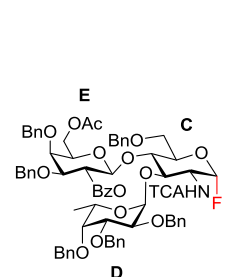

D

28

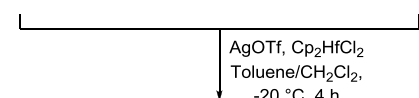

Toluene/ $\mathrm{CH}_{2} \mathrm{Cl}_{2}$

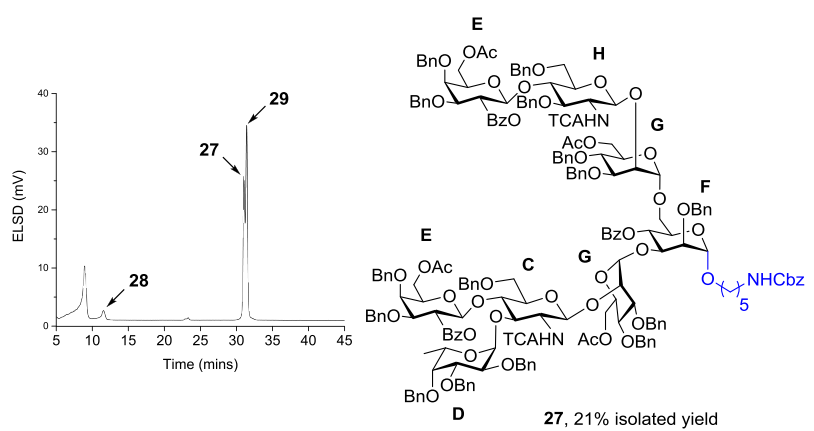

phosphate building blocks and photolabile linker $3 .^{38}$ Unprotected, spacer-free laminarin derivatives 31-34 were chosen as model substrates for comparing the linker performance to that in the earlier study (Scheme 4). In addition to linear $\beta$-(1,3)-heptaglucose 31 , different branched $\beta$-glucans such as penta-glucose 32 as well as octa-glucoses 33 and 34 were prepared (Scheme 4, circled in red). More reactive phosphate building blocks $K$ and $L$ required 4.0 equiv for the
AGA cycle. Extension of the linear $\beta$-(1,3)-glucose backbone employed building block $\mathbf{K}$ bearing an Fmoc group at the C-3 position. For structures with a $\beta$-(1,6)-branch, the linear backbone was first built up using the predefined sequence of glycosyl phosphates $\mathbf{K}$ and $\mathbf{L}$. Building block $\mathbf{L}$ contains a C-3 Fmoc-protected hydroxyl group and a Lev ester on the C-6 hydroxyl. Selective removal of the levulinoyl ester allowed for the extension of the $\beta$-(1,6)-branch. Module IVa $(20 \%$ piperidine in DMF) was used to remove Fmoc, except when Lev was present, in which case module IVc $\left(20 \% \mathrm{Et}_{3} \mathrm{~N}\right.$ in DMF) was employed. Further optimization ${ }^{36}$ resulted in a $20 \%$ reduction in building block consumption. The methanolysis of base-labile protecting groups directly on the solid support was more effective than in solution. The partially protected oligosaccharides were photocleaved from the resin and immediately debenzylated via hydrogenation using the $\mathrm{Pd} / \mathrm{C}$ catalyst ( $60 \mathrm{psi}$ in $<1 \mathrm{~h}$, module VII). With this protocol, only a single purification with reverse-phase HPLC was needed to yield oligosaccharides 31 and $\mathbf{3 2}$ in 30 and $22 \%$ yields, respectively. Branched octasaccharides 33 and $\mathbf{3 4}$ were isolated in lower quantities because these glycans unexpectedly fragmented during hydrogenation to create mixtures of truncated glycans.

\section{CONCLUSIONS}

Traceless photolabile linkers for automated glycan assembly were developed to prepare complex oligosaccharides with a free reducing end. For oligosaccharides with an aminoalkyl spacer at the reducing end, oNB-type linker 3 offers the best photocleavage efficiency, whereas for spacer-free hemiacetal glycans, MeNV-type linker $\mathbf{5}$ is the best choice. The new linker enabled the convergent synthesis of an asymmetrically branched $\mathrm{N}$-glycan octasaccharide and pure laminarins. Levulinoyl ester migration during Fmoc cleavage is suppressed

\section{Scheme 4. Automated Synthesis of Oligo- $\beta$-glucans}

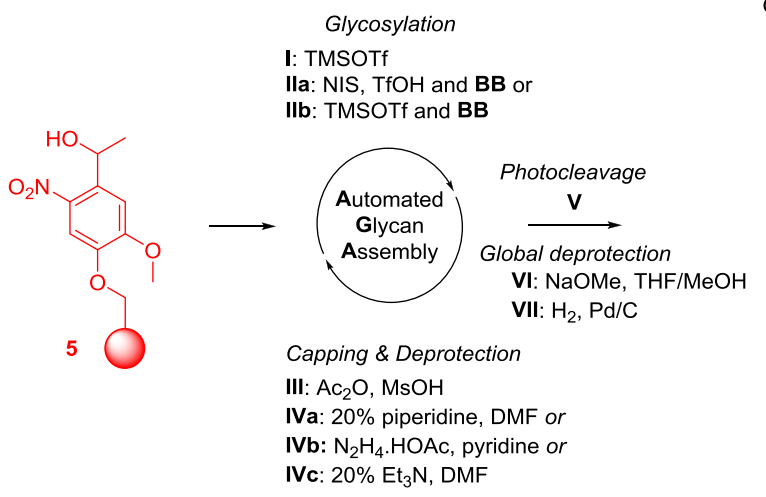

Building Blocks (BB):

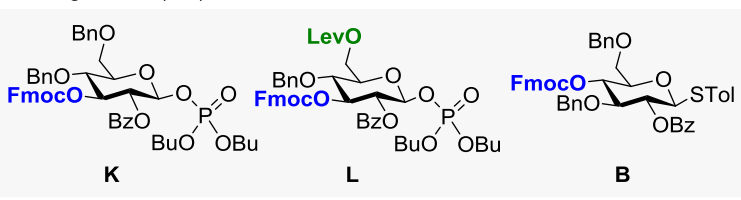

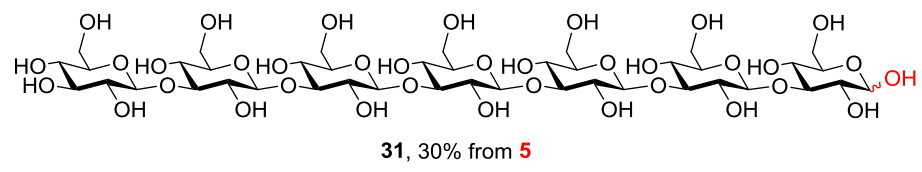
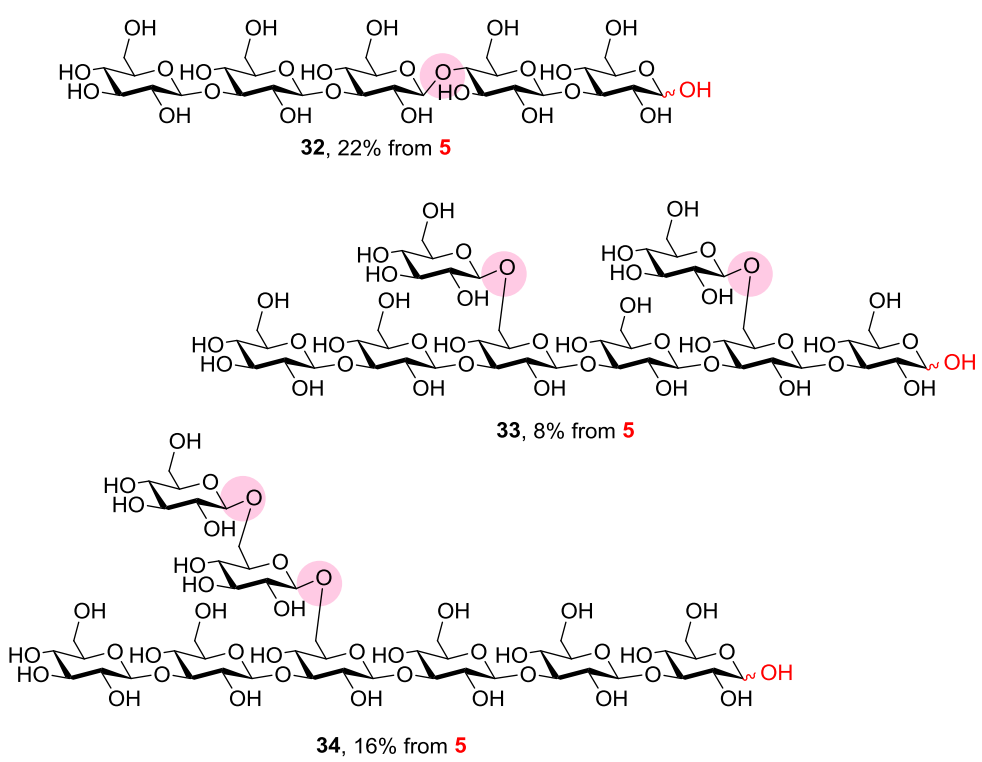
by using $\mathrm{Et}_{3} \mathrm{~N}$ as a base. AGA of four $\beta$-(1,3)-glucans was achieved using $20 \%$ fewer building blocks than previously. A new protocol for the global deprotection of oligosaccharides with a free reducing end was developed. AGA using the new linkers enables access to glycans that can be converted to glycosylating agents to be used on block couplings. Glycans with a free reducing end are valuable standards for mass spectrometry and biological assays.

\section{ASSOCIATED CONTENT}

\section{S Supporting Information}

The Supporting Information is available free of charge on the ACS Publications website at DOI: 10.1021/jacs.9b03769.

Synthesis procedures, AGA modules, and characterization data of glycans, including HPLC chromatograms and NMR spectra (PDF)

\section{AUTHOR INFORMATION}

\section{Corresponding Author}

*Peter.Seeberger@mpikg.mpg.de

\section{ORCID $\odot$}

Martina Delbianco: 0000-0002-4580-9597

Peter H. Seeberger: 0000-0003-3394-8466

Notes

The authors declare no competing financial interest.

\section{ACKNOWLEDGMENTS}

We thank the Max-Planck Society, EU ITN Marie-Curie Program (IMMUNOSHAPE grant no. 642870), Minerva-FastTrack Program, and MPG-FhG Cooperation Project Glyco3Display for generous financial support. We thank Eva Settels and Olaf Niemeyer for technical support.

\section{REFERENCES}

(1) Varki, A.; Cummings, R. D.; Esko, J. D.; Freeze, H. H.; Stanley, P.; Bertozzi, C. R.; Hart, G. W.; Etzler, M. E. Essentials of Glycobiology; Cold Spring Harbor Laboratory Press: 2009.

(2) Hsu, C.-H.; Hung, S.-C.; Wu, C.-Y.; Wong, C.-H. Toward Automated Oligosaccharide Synthesis. Angew. Chem., Int. Ed. 2011, 50, 11872-11923.

(3) (a) Seeberger, P. H. The Logic of Automated Glycan Assembly. Acc. Chem. Res. 2015, 48, 1450-1463. (b) Pardo-Vargas, A.; Delbianco, M.; Seeberger, P. H. Automated Glycan Assembly as an Enabling Technology. Curr. Opin. Chem. Biol. 2018, 46, 48-55.

(4) Wang, Y.; Ye, X.-S.; Zhang, L.-H. Oligosaccharide Assembly by One-Pot Multi-Step Strategy. Org. Biomol. Chem. 2007, 5, 21892200.

(5) Hahm, H. S.; Schlegel, M. K.; Hurevich, M.; Eller, S.; Schuhmacher, F.; Hofmann, J.; Pagel, K.; Seeberger, P. H. Automated Glycan Assembly Using the Glyconeer 2.1 Synthesizer. Proc. Natl. Acad. Sci. U. S. A. 2017, 114, E3385-E3389.

(6) (a) Love, K. R.; Seeberger, P. H. Automated Solid-Phase Synthesis of Protected Tumor-Associated Antigen and Blood Group Determinant Oligosaccharides. Angew. Chem., Int. Ed. 2004, 43, 602605. (b) de Jong, A. R.; Volbeda, A. G.; Hagen, B.; van den Elst, H.; Overkleeft, H. S.; van der Marel, G. A.; Codée, J. D. C. A SecondGeneration Tandem Ring-Closing Metathesis Cleavable Linker for Solid-Phase Oligosaccharide Synthesis. Eur. J. Org. Chem. 2013, 2013, 6644-6655.

(7) (a) Krock, L.; Esposito, D.; Castagner, B.; Wang, C.-C.; Bindschadler, P.; Seeberger, P. H. Streamlined Access to ConjugationReady Glycans by Automated Synthesis. Chem. Sci. 2012, 3, 16171622. (b) Wu, X.; Grathwohl, M.; Schmidt, R. R. A New Phenoxyacetate-Based Linker System for the Solid-Phase Synthesis of Oligosaccharides. Org. Lett. 2001, 3, 747-750. (c) Czechura, P.; Guedes, N.; Kopitzki, S.; Vazquez, N.; Martin-Lomas, M.; Reichardt, N.-C. A New Linker for Solid-Phase Synthesis of Heparan Sulfate Precursors by Sequential Assembly of Monosaccharide Building Blocks. Chem. Commun. 2011, 47, 2390-2392.

(8) (a) Eller, S.; Collot, M.; Yin, J.; Hahm, H. S.; Seeberger, P. H. Automated Solid-Phase Synthesis of Chondroitin Sulfate Glycosaminoglycans. Angew. Chem., Int. Ed. 2013, 52, 5858-5861. (b) Wilsdorf, M.; Schmidt, D.; Bartetzko, M. P.; Dallabernardina, P.; Schuhmacher, F.; Seeberger, P. H.; Pfrengle, F. A Traceless Photocleavable Linker for the Automated Glycan Assembly of Carbohydrates with Free Reducing Ends. Chem. Commun. 2016, 52, 10187-10189.

(9) (a) Schumann, B.; Hahm, H. S.; Parameswarappa, S. G.; Reppe, K.; Wahlbrink, A.; Govindan, S.; Kaplonek, P.; Pirofski, L. A.; Witzenrath, M.; Anish, C.; Pereira, C. L.; Seeberger, P. H. A Semisynthetic Streptococcus Pneumoniae Serotype 8 Glycoconjugate Vaccine. Sci. Transl. Med. 2017, 9, No. eaaf5347. (b) Weishaupt, M. W.; Matthies, S.; Hurevich, M.; Pereira, C. L.; Hahm, H. S.; Seeberger, P. H. Automated Glycan Assembly of a S. Pneumoniae Serotype 3 CPS Antigen. Beilstein J. Org. Chem. 2016, 12, 1440-1446.

(10) (a) Geissner, A.; Reinhardt, A.; Rademacher, C.; Johannssen, T.; Monteiro, J.; Lepenies, B.; Thépaut, M.; Fieschi, F.; Mrázková, J.; Wimmerova, M.; Schuhmacher, F.; Götze, S.; Grünstein, D.; Guo, X.; Hahm, H. S.; Kandasamy, J.; Leonori, D.; Martin, C. E.; Parameswarappa, S. G.; Pasari, S.; Schlegel, M. K.; Tanaka, H.; Xiao, G.; Yang, Y.; Pereira, C. L.; Anish, C.; Seeberger, P. H. MicrobeFocused Glycan Array Screening Platform. Proc. Natl. Acad. Sci. U. S. A. 2019, 116, 1958-1967. (b) Seeberger, P. H. Glycan Arrays and Other Tools Produced by Automated Glycan Assembly. Perspect. Sci. 2017, 11, 11-17. (c) Broecker, F.; Seeberger, P. H. Synthetic Glycan Microarrays. Methods Mol. Biol. 2017, 1518, 227-240. (d) Dallabernardina, P.; Ruprecht, C.; Smith, P. J.; Hahn, M. G.; Urbanowicz, B. R.; Pfrengle, F. Automated Glycan Assembly of Galactosylated Xyloglucan Oligosaccharides and Their Recognition by Plant Cell Wall Glycan-Directed Antibodies. Org. Biomol. Chem. 2017, 15, 9996-10000. (e) Park, S.; Gildersleeve, J. C.; Blixt, O.; Shin, I. Carbohydrate Microarrays. Chem. Soc. Rev. 2013, 42, 4310-4326. (f) Rillahan, C. D.; Paulson, J. C. Glycan Microarrays for Decoding the Glycome. Annu. Rev. Biochem. 2011, 80, 797-823.

(11) (a) Gagarinov, I. A.; Li, T.-H.; Toraño, J. S.; Caval, T.; Srivastava, A. D.; Kruijtzer, J. A. W.; Heck, A. J. R.; Boons, G.-J. Chemoenzymatic Approach for the Preparation of Asymmetric Bi-, Tri-, and Tetra-Antennary N-Glycans from a Common Precursor. J. Am. Chem. Soc. 2017, 139, 1011-1018. (b) North, S. J.; Hitchen, P. G.; Haslam, S. M.; Dell, A. Mass Spectrometry in the Analysis of Nlinked and O-linked Glycans. Curr. Opin. Struct. Biol. 2009, 19, 498506.

(12) (a) Boltjie, T. J.; Kim, J.-H.; Park, J.; Boons, G.-J. ChiralAuxiliary-Mediated 1,2-Cis-Glycosylations for the Solid-Supported Synthesis of a Biologically Important Branched $\alpha$-Glucan. Nat. Chem. 2010, 2, 552-557. (b) Wu, X.; Grathwohl, M.; Schmidt, R. R. Efficient Solid-Phase Synthesis of a Complex, Branched N-Glycan Hexasaccharide: Use of a Novel Linker and Temporary-ProtectingGroup Pattern. Angew. Chem., Int. Ed. 2002, 41, 4489-4493.

(13) Klán, P.; Šolomek, T.; Bochet, C. G.; Blanc, A.; Givens, R.; Rubina, M.; Popik, V.; Kostikov, A.; Wirz, J. Photoremovable Protecting Groups in Chemistry and Biology: Reaction Mechanisms and Efficacy. Chem. Rev. 2013, 113, 119-191.

(14) Holmes, C. P. Model Studies for New o-Nitrobenzyl Photolabile Linkers: Substituent Effects on the Rates of Photochemical Cleavage. J. Org. Chem. 1997, 62, 2370-2380.

(15) Gude, M.; Ryf, J.; White, P. D. An Accurate Method for the Quantitation of Fmoc-Derivatized Solid Phase Supports. Lett. Pept. Sci. 2002, 9, 203-206.

(16) Hoffmann, J.; Kazmaier, U. Development of a New NPPOCDerived Photolabile Protecting Group Suitable for Cyclizations via Ring Closing Metathesis. Curr. Org. Synth. 2015, 12, 475-483.

(17) Wilcox, M.; Viola, R. W.; Johnson, K. W.; Billington, A. P.; Carpenter, B. K.; McCray, J. A.; Guzikowski, A. P.; Hess, G. P. 
Synthesis of Photolabile Precursors of Amino Acid Neurotransmitters. J. Org. Chem. 1990, 55, 1585-1589.

(18) Salmi, C.; Letourneux, Y.; Brunel, J. M. Efficient Synthesis of Various Secondary Amines Through a Titanium(IV) isopropoxideMediated Reductive Amination of Ketones. Lett. Org. Chem. 2006, 3, 396-401.

(19) Bartetzko, M. P.; Schuhmacher, F.; Hahm, H. S.; Seeberger, P. H.; Pfrengle, F. Automated Glycan Assembly of Oligosaccharides Related to Arabinogalactan Proteins. Org. Lett. 2015, 17, 4344-4347.

(20) Šlomek, T.; Mercier, S.; Bally, T.; Bochet, C. G. Photolysis of Ortho-Nitrobenzylic Derivatives: The Importance of the Leaving Group. Photochem. Photobiol. Sci. 2012, 11, 548-555.

(21) (a) Ohtsubo, K.; Marth, J. D. Glycosylation in Cellular Mechanisms of Health and Disease. Cell 2006, 126, 855-867. (b) Lauc, G.; Pezer, M.; Rudan, I.; Campbell, H. Mechanisms of Disease: The Human N-Glycome. Biochim. Biophys. Acta, Gen. Subj. 2016, 1860, 1574-1582.

(22) Freeze, H. H. Genetic Defects in the Human Glycome. Nat. Rev. Genet. 2006, 7, 537-551.

(23) Zhao, Y.-Y.; Takahashi, M.; Gu, J.-G.; Miyoshi, E.; Matsumoto, A.; Kitazume, S.; Taniguchi, N. Functional Roles of $\mathrm{N}$-Glycans in Cell Signaling and Cell Adhesion in Cancer. Cancer Sci. 2008, 99, 13041310.

(24) Lau, K. S.; Partridge, E. A.; Grigorian, A.; Silvescu, C. I.; Reinhold, V. N.; Demetriou, M.; Dennis, J. W. Complex N-Glycan Number and Degree of Branching Cooperate to Regulate Cell Proliferation and Differentiation. Cell 2007, 129, 123-134.

(25) (a) Chiesa, M. V.; Schmidt, R. R. Synthesis of an AsparagineLinked Heptasaccharide - Basic Structure of N-Glycans. Eur. J. Org. Chem. 2000, 2000, 3541-3554. (b) Jonke, S.; Liu, K. G.; Schmidt, R. R. Solid-Phase Oligosaccharide Synthesis of a Small Library of $\mathrm{N}$ Glycans. Chem. - Eur. J. 2006, 12, 1274-1290.

(26) (a) Walczak, M. A.; Hayashida, J.; Danishefsky, S. J. Building Biologics by Chemical Synthesis: Practical Preparation of Di- and Triantennary N-Linked Glycoconjugates. J. Am. Chem. Soc. 2013, 135, 4700-4703. (b) Wang, P.; Zhu, J.; Yuan, Y.; Danishefsky, S. J. Total Synthesis of the 2,6-Sialylated Immunoglobulin G Glycopeptide Fragment in Homogeneous Form. J. Am. Chem. Soc. 2009, 131, 16669-16671. (c) Wu, B.; Hua, Z.; Warren, J. D.; Raganathan, K.; Wan, Q.; Chen, G.; Tan, Z.; Chen, J.; Endo, A.; Danishefsky, S. J. Synthesis of the Fucosylated Biantennary N-Glycan of Erythropoietin. Tetrahedron Lett. 2006, 47, 5577-5579.

(27) (a) Manabe, Y.; Shomura, H.; Minamoto, N.; Nagasaki, M.; Takakura, Y.; Tanaka, K.; Silipo, A.; Molinaro, A.; Fukase, K. Convergent Synthesis of a Bisecting N-Acetylglucosamine (GlcNAc)Containing N-Glycan. Chem. - Asian J. 2018, 13, 1544-1551. (b) Nagasaki, M.; Manabe, Y.; Minamoto, N.; Tanaka, K.; Silipo, A.; Molinaro, A.; Fukase, K. Chemical Synthesis of a Complex-Type NGlycan Containing a Core Fucose. J. Org. Chem. 2016, 81, 1060010616.

(28) (a) Mönnich, M.; Eller, S.; Karagiannis, T.; Perkams, L.; Luber, T.; Ott, D.; Niemietz, M.; Hoffman, J.; Walcher, J.; Berger, L.; Pischl, M.; Weishaupt, M.; Wirkner, C.; Lichtenstein, R. G.; Unverzagt, C. Highly Efficient Synthesis of Multiantennary Bisected N-Glycans Based on Imidates. Angew. Chem., Int. Ed. 2016, 55, 10487-10492. (b) Ott, D.; Seifert, J.; Prahl, I.; Niemietz, M.; Hoffman, J.; Guder, J.; Mönnich, M.; Unverzagt, C. Modular Synthesis of Core Fucosylated N-Glycans. Eur. J. Org. Chem. 2012, 2012, 5054-5068. (c) Eller, S.; Schuberth, R.; Gundel, G.; Seifert, J.; Unverzagt, C. Synthesis of Pentaantennary N-Glycans with Bisecting GlcNAc and Core Fucose. Angew. Chem., Int. Ed. 2007, 46, 4173-4175. (d) Schuberth, R.; Unverzagt, C. Synthesis of a N-glycan nonasaccharide of the bisecting type with additional core-fucose. Tetrahedron Lett. 2005, 46, 42014204.

(29) (a) Li, T.; Liu, L.; Wei, N.; Yang, J.-Y.; Chapla, D. G.; Moremen, K. W.; Boons, G.-J. An Automated Platform for the Enzyme-Mediated Assembly of Complex Oligosaccharides. Nat. Chem. 2019, 11, 229-236. (b) Liu, L.; Prudden, A. R.; Capicciotti, C. J.; Bosman, G. P.; Yang, J.-Y.; Chapla, D. G.; Moremen, K. W.;
Boons, G.-J. Streamlining the Chemoenzymatic Synthesis of Complex $N$-Glycans by a Stop and Go Strategy. Nat. Chem. 2019, 11, 161-169. (c) Wang, Z.; Chinoy, Z. S.; Ambre, S. G.; Peng, W.; McBride, R.; de Vries, R. P.; Glushka, J.; Paulson, J. C.; Boons, G.-J. A General Strategy for the Chemoenzymatic Synthesis of Asymmetrically Branched N-Glycans. Science 2013, 341, 379-383.

(30) Koizumi, A.; Matsuo, I.; Takatani, M.; Seko, A.; Hachisu, M.; Takeda, Y.; Ito, Y. Top-Down Chemoenzymatic Approach to a HighMannose-Type Glycan Library: Synthesis of a Common Precursor and Its Enzymatic Trimming. Angew. Chem., Int. Ed. 2013, 52, 74267431.

(31) Li, L.; Liu, Y.; Ma, C.; Qu, J.; Calderon, A. D.; Wu, B.; Wei, N.; Wang, X.; Guo, Y.; Xiao, Z.; Song, J.; Sugiarto, G.; Li, Y.; Yu, H.; Chen, X.; Wang, P. G. Efficient Chemoenzymatic Synthesis of an $N$ Glycan Isomer Library. Chem. Sci. 2015, 6, 5652-5661.

(32) (a) Shivatare, S. S.; Chang, S.-H.; Tsai, T.-I.; Ren, C.-T.; Chuang, H.-Y.; Hsu, L.; Lin, C.-W.; Li, S.-T.; Wu, C.-Y.; Wong, C.-H. Efficient Convergent Synthesis of Bi-, Tri-, and Tetra-antennary Complex Type N-Glycans and Their HIV-1 Antigenicity. J. Am. Chem. Soc. 2013, 135, 15382-15391. (b) Shivatare, S. S.; Chang, S.-H.; Tsai, T.-I.; Tseng, S. Y.; Shivatare, V. S.; Lin, Y.-S.; Cheng, Y.-Y.; Ren, C.T.; Lee, C.-C. D.; Pawar, S.; Tsai, C.-S.; Shih, H.-W.; Zeng, Y.-F.; Liang, C.-H.; Kwong, P. D.; Burton, D. R.; Wu, C.-Y.; Wong, C.-H. Modular Synthesis of $\mathrm{N}$-glycans and Arrays for the Hetero-Ligand Binding Analysis of HIV Antibodies. Nat. Chem. 2016, 8, 338-346.

(33) Mukaiyama, T.; Jona, H. Glycosyl fluoride - A Superb Glycosyl Donor in Glycosylation. Proc. Jpn. Acad., Ser. B 2002, 78, 73-83.

(34) (a) Lougheed, B.; Ly, H. D.; Wakarchuk, W. W.; Withers, S. G. Glycosyl Fluorides Can Function as Substrates for Nucleotide Phosphosugar-dependent Glycosyltransferases. J. Biol. Chem. 1999, 274, 37717-37722. (b) Williams, S. J.; Withers, S. G. Glycosyl Fluorides in Enzymatic Reactions. Carbohydr. Res. 2000, 327, 27-46.

(35) Markad, S. D.; Schmidt, R. R. Temporary Carbohydrate Diol Protection with Ester Groups - Orthogonality under Solid-Phase Oligosaccharide Synthesis Conditions. Eur. J. Org. Chem. 2009, 2009, 5002-5011.

(36) (a) Delbianco, M.; Kononov, A.; Poveda, A.; Yu, Y.; Diercks, T.; Jiménez-Barbero, J.; Seeberger, P. H. Well-Defined Oligo- and Polysaccharides as Ideal Probes for Structural Studies. J. Am. Chem. Soc. 2018, 140, 5421-5426. (b) Yu, Y.; Kononov, A.; Delbianco, M.; Seeberger, P. H. A Capping Step During Automated Glycan Assembly Enables Access to Complex Glycans in High Yield. Chem. - Eur. J. 2018, 24, 6075-6078.

(37) (a) Bohé, L.; Crich, D. Double Diastereoselection, Regioselectivity, and the Importance of Donor-Acceptor Complementarity in the Stereoselectivity of Glycosylation Reactions. Trends Glycosci. Glycotechnol. 2010, 22, 1-15. (b) Vetvicka, V.; Novak, M. Beta-Glucan, Structure, Chemistry and Specific Application; Bentham Science Publishers: 2013.

(38) (a) Weishaupt, M. W.; Hahm, H. S.; Geissner, A.; Seeberger, P. H. Automated Glycan Assembly of Branched $\beta-(1,3)$-glucans to Identify Antibody Epitopes. Chem. Commun. 2017, 53, 3591-3594. (b) Weishaupt, M. W.; Matthies, S.; Seeberger, P. H. Automated Solid-Phase Synthesis of a $\beta-(1,3)$-Glucan Dodecasaccharide. Chem. Eur. J. 2013, 19, 12497-12503. 